\title{
Access to Institutional Delivery Services and Associated Factors among Mothers in Jimma Zone, Southwest Ethiopia
}

Qaro Qanche Kayrite ( $\nabla$ qaroqanche@gmail.com )

Mizan-Tepi University https://orcid.org/0000-0002-8051-2529

\section{Waju Beyene Salgedo}

Jimma University

Tesfaye Dagne Weldemarium

Jimma University

Research article

Keywords: access, dimensions, institutional delivery services, mothers, Jimma, Southwest Ethiopia

Posted Date: November 15th, 2019

DOl: https://doi.org/10.21203/rs.2.17365/v1

License: (c) (i) This work is licensed under a Creative Commons Attribution 4.0 International License.

Read Full License 


\section{Abstract}

Background Poor utilization of institutional delivery services has been identified as a major contributory factor to poor maternal and newborn outcomes. Previous studies have tried to measure access in terms of utilization while it has different dimensions that need to be measured separately. Therefore, this study assessed the four dimensions of access (geographic accessibility, perceived availability, affordability, and acceptability) and associated factors.

Methods A community based cross-sectional study design was used to undertake this study from March 16 to April 15, 2018, in Jimma Zone. The sample size for this study was 605 mothers who had given birth in the last six months preceding the study. Multi-variable binary logistic regression was used to identify factors associated with the four dimensions of access by using AOR with $95 \% \mathrm{Cl}$. Ethical clearance was obtained from Jimma University Institutional Review Board.

Results Five hundred and ninety-three mothers participated in this study resulting in a response rate of $98 \%$. Four hundred five (68\%), 273(46\%), 279(47\%) and 273(46\%) had geographic, perceived availability, affordability and acceptability access to institutional delivery services respectively. Antenatal $[A O R=3.74(1.56,8.98)]$, occupation of mother $[A O R=5.10(1.63,15.88)]$, and residence $[A O R=1.93(1.13$, 3.29)] were independently associated with geographic accessibility. Household graduation $[A O R=1.46(1.03,2.06)]$, residence $[A O R=1.74(1.17,2.59)]$ and $A N C[A O R=3.80(1.38,10.50)]$ were independently associated with perceived availability. Moreover, wealth quintile [AOR=11.60(6.02, 22.35)], ANC [AOR=3.48(1.36, 9.61)] and occupation of husband [AOR=3.63(1.51, 8.74)] were independently associated with affordability. Lastly, mother's education [AOR=2.69(1.42, 5.09)], residence $[A O R=2.60(1.66,4.08)]$ and household graduation $[A O R=3.12(2.16,4.50)]$ were independently associated with acceptability of institutional delivery services.

Conclusions Moderate proportions of mothers have geographic accessibility to institutional delivery services but access to the other three dimensions was low. ANC visits of 4 and above, occupation of mothers' husbands, urban residence, graduation of mother's household as a model family, higher wealth quintiles of mother's household, and maternal educational level of secondary school and above significantly affect access to institutional delivery services. Thus, it was recommended that concerned bodies should give special attention to ANC service, female education, training of model families, and enhancement of household wealth through job creation opportunities to improve access to institutional delivery services.

\section{Introduction}

Access to health care represents the empowerment of an individual to use health care and reflects an individual's capacity to benefit from services, given the individual's circumstances and experiences in relation to the health care system. Policies concerned with access to care imply an obligation on decisionmakers to not just make services available but to actively empower individuals to use those services 
when needed. Differences in access (i.e. empowerment) between individuals cause differences in the use of health care services(1).

Access to health care has four dimensions: geographic accessibility, availability, affordability (or financial access) and acceptability (or cultural access). Geographic accessibility is concerned with the relationship between the location of health care facilities (supply factor) and the location of those who need these services and their transportation opportunities (demand factors). Availability includes issues such as the level of supply of staff or drugs, the degree of fit between the hours of service of health care facilities (opening hours) and the times that individuals need services to be provided. Affordability is concerned with the degree of fit between the full costs to the individual using the service and the individual's ability to pay in the context of the household budget and other demands on that budget. Acceptability is concerned with the fit between provider and patient attitudes towards and expectations of each other $(1,2)$.

Generally, access can be looked at from two perspectives each having the four dimensions in them. These are the demand side and supply side perspectives. Demand-side perspective includes factors that influence health service users as individuals, households or at the community level and include geographic accessibility, availability of health services, affordability, and acceptability. Supply-side perspective factors are those that function at the service delivery level and are beyond the control of health service users, for instance, inadequate skilled personnel. Similar to demand-side factors, they include geographic accessibility, availability, affordability, and acceptability of health services $(3,4)$.

Factors which affect access to institutional delivery services can be categorized under the demand and supply-side perspectives and some of these include service location/distance, means of transportation, education, income, information, decision making power, waiting time, users attitudes and expectations, and provider attitudes among others (3-6).

Ideally, healthcare services should be physically accessible and available, economically affordable, and psychosocially acceptable to clients at all times. This is particularly important for vulnerable populations with specific needs, such as pregnant and delivering mothers(4).

Poor access to and use of institutional delivery services have been identified as a major contributory factor to high maternal and newborn mortality in sub-Saharan African countries, including Ethiopia(5). Worldwide, maternal mortality is unacceptably high. In 2010, 287000 women died during and following pregnancy and childbirth. Almost all maternal deaths (99\%) occur in developing countries and more than half of these deaths occur in sub-Saharan Africa(7).

In Ethiopia, poor access to institutional delivery services is reflected by its high maternal mortality ratio (MMR). According to 2016 Ethiopian Demographic and Health Survey (EDHS), MMR was estimated to be 412 per 100,000 live births(8). 
Health facility delivery is encouraged as a single most important strategy in preventing maternal and neonatal morbidity and mortality. Since 2000, the United Nations' Millennium Development Goals have facilitated significant reductions in maternal morbidity and mortality worldwide. However, despite more focused efforts made especially by low- and middle-income countries, targets were largely unmet in subSaharan Africa, where women are plagued by many challenges in seeking obstetric care(9).

Institutional delivery service utilization is one of the keys and proven interventions to reduce maternal death. It ensures safe birth, reduces both actual and potential complications and maternal death and increases the survival of most mothers and newborns (10). Despite this fact, home delivery is common in many developing countries including Ethiopia. Although institutional delivery has been promoted in Ethiopia, home delivery is still common, primarily in hard-to-reach areas. The 2016 EDHS showed that only $26 \%$ of live births were delivered in a health facility in the 5 years before the survey whereas home delivery was $73 \%$ and $1 \%$ deliveries in other places. For rural women, the report showed that only $20 \%$ of the births took place in a health facility and $80 \%$ of them delivered at home. The report also showed that for the Oromia region, institutional delivery was only $18.8 \%$ which is the third-lowest slightly above Afar (14.7\%) and Somali (17.9\%) regions(8).

Studies conducted in different parts of the Oromia region reported that institutional delivery ranges from $12.3 \%$ in Munisa woreda of Arsi Zone to $47 \%$ in Goba Woreda of Bale Zone $(6,11-14)$. These studies show that significant proportions of mothers in the region yet have no access to institutional delivery services and more than $50 \%$ of the births are taking place outside the health facilities without the help of health professionals where the risk of maternal death is very high.

The government of Ethiopia has developed an ambitious plan, the health sector transformation plan (HSTP), which aims to reduce maternal mortality ratio from 420 per 100,000 live births to 199 per 100,000 live births and to increase deliveries attended by skilled health personnel to $90 \%$ by the end of 2020 (15). But, these targets will never be met unless the level of current access to institutional delivery services is known and the factors that affect access are clearly identified in order to take appropriate measures.

There was substantial research and literature on institutional delivery service utilization and barriers to institutional delivery service utilization as it is an important international public health issue. However, it is not appropriate to measure access in terms of utilization as access has different dimensions that need to be measured separately. Moreover, there were no previous studies that have specifically focused on the four dimensions of access.

Therefore, the main objective of this study was to assess access to institutional delivery service and its associated factors with respect to the four dimensions of access.

\section{Methods}


This study was conducted in six randomly selected districts of Jimma Zone (Mencho, Gomma, Nano Benja, Seka Chokorsa, Gumay, and Kersa), Southwest Ethiopia, from March 16 to April 15, 2018. Jimma zone is one of the 17 zones found in Oromia regional state, located $350 \mathrm{~km}$ southwest of Addis Ababa, the capital city of Ethiopia. There are 20 rural districts and two town administrations with a total of $561 \mathrm{Kebeles} / \mathrm{villages}$ in the zone. The estimated total population of the zone was 3,312,914 among which 603,222 were reproductive age women among which 103721 are pregnant. Concerning health facilities, there is 1 tertiary hospital, 8 primary hospitals, 122 health centers and 513 health posts in the zone.

Community-based cross-sectional study design was used, employing both quantitative and qualitative methods, to undertake this study. The qualitative method was used to support the findings of quantitative results in order to explore and understand what is behind mere quantitative figures.

The source population for this study was all women of reproductive age group (15-49 years) and the study population was randomly selected mothers who lived at least for six months in the selected kebeles and who have given birth in the last six months preceding the study.

Single population proportion formula was used to determine sample size with assumptions of $P=50 \%$ (proportion of mothers having access to institutional delivery service), 95\% confidence level, and 5\% margin of error. And a design effect of 1.5 was used to account for the sampling variability of multi-stage sampling. The calculated sample size was 576 and $5 \%$ added for an expected non-response rate to have a final sample size of 605 for the quantitative study.

For qualitative data, four focused group discussions (FGDs) were carried out; two with women health development army leaders, one with home-delivered mothers and one with health facility delivered mothers. The FGD participants were identified by the suggestion of health extension workers and community elders. Each FGD consisted of 8-10 mothers.

A multi-stage sampling technique was employed taking the districts as primary sampling units (PSU), kebeles/villages from the selected districts as secondary sampling units (SSU) and mothers at households from the selected kebeles as tertiary sampling units (TSU). Thirty percent of the districts and kebeles were selected by lottery method. Then, depending on the number of mothers who have given birth in the last 6 months preceding the study, the sample size was proportionally allocated to the selected kebeles. Finally, a simple random sampling (SRS) method was used to get mothers for an interview at a household level.

Data collection tools were prepared in English and then translated to the local language, i.e. Afan Oromo, by a language expert, and then back to English by another language expert to ensure consistency. Two days of training was given for data collectors and supervisors before data collection about the aim of the study and data collection techniques by going through the questionnaire question by question.

Six data collectors who were fluent in speaking and writing the local language participated in the data collection process using a pretested interviewer-administered structured questionnaire for the quantitative 
part. For the qualitative part, an interview guide was used for FGD and the discussions were recorded using a tape recorder. In addition, hand-written notes were taken as well. The FGDs were moderated by the respective district supervisors who were fluent in speaking and writing the local language.

A pretest was conducted in a nearby district, (Omonada district), on $10 \%$ of the sample size to determine the clarity of the items and the consistency of the responses. During actual data collection, the filled questionnaires were checked for consistency and completeness each day and submitted to the supervisors. Data was entered into epi-Data version 3.1 by two persons separately and the two files were validated for consistency, and necessary corrections were made before exporting the data into SPSS for analysis.

The dependent variables of measurement were: Physical accessibility, Perceived availability, Affordability, and Acceptability while the independent variable were Socio-demographic variables (age, religion, ethnicity, residence,marital status), Socio-economic variables (HH wealth index, mother's education, husband's education, mother's occupation, husband's occupation), Obstetric \& related variables (parity, ANC use), and Household-level variables (HH headship, Family size, $\mathrm{HH}$ model status).

\section{Operational definitions}

- Access to institutional delivery service-in this study, access to institutional delivery service was measured by its four dimensions separately; geographic accessibility, availability, affordability, and acceptability.

- Institutional delivery-is the delivery of a baby that takes place in a health facility; both public and private facilities.

- Geographic accessibility-is travel time from mothers' homes to the nearest health facility on foot walk. In this study, mothers who live within a distance of 60 minutes on foot walk from the nearest health facility were considered having geographic accessibility (16-18); otherwise not accessible.

- Perceived availability-in this study, availability of institutional delivery services was measured from the mothers' perspective by ten items which asked mothers' perceived availability of institutional delivery services with major components of availability of qualified professionals, availability of drugs and supplies, and availability of laboratory services among others. The items were measured on a 5 points agreement Likert scale and mean scores were calculated for each mother. Finally, the mean score for the total sample was computed and if a mother's mean score was greater than or equal to the sample mean, then she was considered as having perceived availability; otherwise not.

- Affordability-is when mothers or families are able and willing to pay for the cost of transportation, prescribed medication/services, staying cost at a facility, and cover the opportunity costs related to health facility delivery without any borrowing or sell of basic household resources. There were four items that assessed these four types of costs. These items included whether mothers have the ability and willingness to afford the direct cost of prescribed medicines and supplies, indirect costs related to transportation and staying at the facility, and the presence of family members to accompany them 
to the facility. These costs should be afforded without borrowing money or selling of basic household assets. If the mother answered 'yes' to all the four questions, she was considered able to afford; otherwise not.

- Acceptability-is when the available delivery services meet the social and cultural expectations of mothers, families, and communities; where the major components included decision making power of mothers on the place of delivery, perceived/experienced cleanliness of health facilities, fear of interference by strangers, fear of maltreatment by health professionals, discrimination and stigma among others. Fifteen items were developed and measured on 5 points agreement Likert scale and mean scores were calculated for each mother. Finally, the mean score for the total sample was computed and if a mother's mean score was greater than or equal to the sample mean, then she was considered as having acceptability of IDS; otherwise not.

- Household wealth index-is households' living status and was constructed by principal component analysis using household asset data on housing conditions like type of floor, material of wall, material of roof; ownership of assets like radio, TV, telephone, vehicle; presence of functional latrine, source of drinking water, ownership of domestic animals, ownership of farmland and amount of grain harvested in the last production year among others.

With regard to data processing and analysis, the collected data were checked for consistency, then coded and entered into epi-Data version 3.1. After validation of duplicated files for consistency, it was exported to SPSS version 20 for cleaning and analysis.

Principal component analysis (PCA) was conducted to estimate the wealth index of households. When using PCA, all assumptions of PCA such as metric level or dummy coded variables, minimum sample size of 50 , cases to items ratio of 5 to 1 or more, two or more correlation of 0.3 or more on correlation matrix, removing items with sampling adequacy less than 0.5 , and significance of Bartlett test of sphericity were checked. Varimax rotation was used to get better loading variables to the components. Additionally, variables with communality less than 0.5 were removed and then variables with complex structures (having loadings of 0.4 or more on more than one component) on the rotated component matrix were removed. Components with only one variable loading on them were also checked and were removed. Finally, seven components were formed and they explained $67 \%$ of the total variability. The reliability of variables within each component was assessed and all of the variables in the components had Cronbach alpha of 0.6 and above.

Means and proportions were used as descriptive statistics and summary measures; and tables, graphs, and charts were used to present the results of this study. To identify associated factors, first, the chisquare test was run for individual study variables for each of the access dimensions. Variables that fulfilled chi-square assumptions were passed for simple logistic regression. Then, variables with a p-value of $\leq 0.25$ on simple logistic regression were taken as candidates for multivariable logistic regression using $10 \%$ for probability of entry and $15 \%$ for probability of removal. A backward likelihood ratio method was used for variable selection. Finally, four separate models were fitted to show the effect of significant predictor variables on the outcome variables at a $p$-value of $\leq 0.05$. The adequacies of the models were 
checked by Hosmer and Lemeshow test of goodness of fit at $p \geq 0.1$. Nagelkerke pseudo R squared and the overall prediction powers of the models from the classification tables were also reported. Using an adjusted odds ratio (AOR) with $95 \%$ confidence interval, the association of dependent and independent variables were interpreted.

Qualitative data was first transcribed, coded and categorized to form primary themes based on the objectives of the study. Besides, quotes of participants that supported or contradicted the key quantitative findings were triangulated with the quantitative findings during the discussion of the results.

\section{Results}

\section{Socio-demographic and Economic Characteristics of mothers}

Out of the 605 total sample size, 593 mothers participated in this study resulting in a response rate of $98 \%$. The mean age of the mothers was 31years with a standard deviation of 6 years, and $211(36 \%)$ were in the age group $26-30$ years. The majority, $436(74 \%)$ of the mothers were Muslim in religion and more than three fourth, $460(78 \%)$ of them were Oromo in ethnicity. About $77 \%$ of the mothers live in rural areas and nearly all of the mothers, 583(98\%) were currently in marriage. Approximately half $292(49 \%)$ were housewives followed by farmers (38.6\%). Two hundred twenty-two (37\%) of the mothers can read and write whereas only $117(20 \%)$ of them attended secondary education and above. Their husbands were slightly more educated in which $133(22 \%)$ attended secondary education and above (Table 1).

\section{Household-level characteristics of mothers}

The average family size was 5.46 persons per household with a standard deviation of 1.7. More than half, $330(56 \%)$ of the mothers' households had five or fewer members in the family and the majority of the households, $571(96 \%)$ were headed by husbands. Two hundred eighty $(47 \%)$ of the mothers'households were graduated by health extension workers as model families (Table 2).

\section{Obstetric and related characteristics of mothers}

The average number of children per mother was 3.4, and 395(66.6\%) of the mothers had 2-4 children, $135(22.8 \%)$ had 5 or more children, and $63(10.6 \%)$ of the mothers had one child. Almost all of the mothers, $585(99 \%)$ had a history of ANC follow up for their last pregnancy. Among those who had ANC follow up, 320(54.7\%) had 4 and more visits, $238(40.7 \%)$ had $2-3$ visits and $27(4.6 \%)$ had only a single visit during their last pregnancy. (Figure 1: Number of ANC visits during last pregnancy among mothers in Jimma zone, Southwest Ethiopia, 2018) 


\section{Dimensions of access to institutional delivery services}

From the total 593 respondents, slightly more than two-third, 405(68\%), had geographic access to institutional delivery services while in the other three dimensions of access less than half of the mothers had access to institutional delivery services. Two hundred seventy-three (46\%), 279(47\%) and 273(46\%) of the mothers had perceived availability, affordability, and acceptability of institutional delivery services respectively. (Figure 2: Dimensions of access to institutional delivery services among mothers in Jimma zone, Southwest Ethiopia, 2018)

\section{Factors associated with geographic accessibility to institutional delivery services}

From the simple logistic regression analysis 12 variables such as religion, ethnicity, residence, mother's occupation, husband's occupation, mother's educational level, husband's educational level, family size, household model status, parity, number of ANC visits, and wealth index were found to be candidates for multivariable logistic regression. After running multivariable logistic regression mothers' occupation, residence, and ANC visits during last pregnancy were found to be independently associated with geographic accessibility to institutional delivery services (IDS) at a p-value of less than 0.05 (Table 3 ).

This study found that mothers' occupation was significantly associated with geographic accessibility to institutional delivery services. Employed mothers were 5 times more likely to have geographic accessibility to institutional delivery services when compared to mothers who were farmers (AOR = $5.10[1.63,15.88])$. Another variable that was associated with geographic accessibility was the mothers' residence. Mothers who live in urban areas were about 2 times more likely to have geographic accessibility to institutional delivery services when compared to mothers living in rural areas (AOR = $1.93[1.13,3.29])$.

Number of ANC visits during the last pregnancy was also another variable that was significantly associated with geographic accessibility to institutional delivery services. Mothers who had 4 or more ANC visits during their last pregnancy were about 4 times more likely to have geographic accessibility to institutional delivery services when compared to mothers who had only a single ANC visit during their last pregnancy $(A O R=3.74[1.56,8.98])$. Moreover, mothers who had 2-3 ANC visits during their last pregnancy were 3 times more likely to have geographic accessibility to institutional delivery services when compared to mothers who had only a single ANC visit during their last pregnancy $(A O R=3.0[1.26$, 7.17]).

\section{Factors associated with Perceived availability of institutional delivery services}


Ten variables were identified as candidates for multivariable logistic regression and after running multivariable logistic regression three variables were found significantly associated with the perceived availability of IDS. These variables include number of ANC visits, residence and model status of a mother's household (Table 4).

Mothers who had 4 or more ANC visits during their last pregnancy were about 4 times more likely to have perceived availability of IDS when compared to mothers who had only one ANC visit during their last pregnancy $(A O R=3.80[1.38,10.50])$. Mothers who live in urban areas were about 2 times more likely to have perceived availability of IDS when compared to their rural counterparts (AOR $=1.74[1.17,2.59])$.

Graduation of a mother's household as a model family was another variable that was significantly associated with the perceived availability of IDS. Mothers whose households were graduated by HEWs as a model family was about 1.5 times more likely to have perceived availability of IDS when compared to non-model families $(A O R=1.46[1.03,2.06])$.

\section{Factors associated with the affordability of institutional delivery services}

Eight variables were found to be candidates for multivariable logistic regression and after running multivariable logistic regression, three variables were significantly associated with the affordability of IDS. These three variables were wealth quintile of mother's household, number of ANC visits and husband's occupation (Table 5).

Mothers in the highest wealth quintile were about 12 times more likely to be able to afford institutional delivery services when compared to mothers in the lowest wealth quintile (AOR $=11.60[6.02,22.35])$. Similarly, mothers in the fourth, middle and second wealth quintiles each were about 3 times more likely to be able to afford institutional delivery services when compared to mothers in the lowest wealth quintile $(A O R=3.11[1.71,5.68], 3.04[1.66,5.58]$ and $2.83[1.55,5.16])$ respectively.

Mothers who had four or more ANC visits during their last pregnancy were about 3.5 times more likely to afford institutional delivery services when compared to mothers who had only one ANC visit (AOR = $3.48[1.36,9.61])$. Again, mothers who had 2-3 ANC visits were 3 times more likely to afford institutional delivery services when compared to mothers who had only one ANC visit(AOR $=3.37[1.31,8.25])$.

The husband's occupation was another variable that was independently associated with the affordability of institutional delivery services. Mothers whose husbands were employed were about 4 times more likely to afford institutional delivery services when compared to mothers whose husbands were farmers ( $A O R=$ $3.63[1.51,8.74])$.

\section{Factors associated with acceptability of institutional delivery services}


Seven candidate variables were selected for multivariable logistic regression and after running multivariable logistic regression, three variables (mother's educational level, residence, and graduation of mother's $\mathrm{HH}$ as a model family by HEWs) were found to be independently associated with acceptability of IDS (Table 6).

Mothers who have achieved secondary education and above were about 3 times more likely to accept institutional delivery services when compared to mothers who cannot read \& write (AOR = 2.69[1.42, 5.09]). Similarly, mothers who live in urban areas were about 3 times more likely to accept institutional delivery services when compared to mothers who live in rural areas $(A O R=2.60[1.66,4.08])$.

Graduation of mother's HH as a model family by HEWs was also significantly associated variable with the acceptability of institutional delivery services. Mothers whose households were graduated as a model family by HEWs were 3 times more likely to accept institutional delivery services when compared to mothers of non-model families (AOR $=3.12[2.16,4.50])$.

\section{Qualitative Study Results}

A total of four FGDs were carried out; two with women health development army leaders, one with homedelivered mothers and one with health facility delivered mothers. Overall, 35 mothers had participated in the discussions and each FGD consisted of 8-10 mothers. The discussions had taken 60-90 minutes each.

The participants have identified many factors that hinder mothers from accessing institutional delivery services. The majority of the home-delivered participants reported that there are few health centers in their area and even the available ones are very far from their homes. They also complained that even if they attend full ANC visits at the nearby health posts in their Kebele, they deliver at home because of the long distance from the health facilities and lack of ambulance services. Participants also reported that home delivery is very common when labor comes at night.

Some of the health facility delivered mothers raised shortage and/or unavailability of health professionals who give immediate care on arrival. Shortage of prescribed medicines and supplies, as well as unavailability of laboratory services, are also reported by the majority of the health facility delivered mothers as problems that affect their intention for subsequent utilization and recommendation for other mothers.

Almost all of the participants in all of the four groups reported difficulty paying for transport costs and the cost of medicines that are not available in the health centers which are bought from private pharmacies. Some mothers also mentioned that their husbands are not voluntary to accompany them to the health centers while others reported unavailability of somebody else who takes care of their house and children when they went to a health center for delivery. 
Lack of respect for mothers' privacy and dignity is the major issue raised by the majority of the health facility delivered mothers. These are reported as delaying of care after arrival, lack of privacy during labor, insulting mothers in labor, hitting mothers in labor and denying relatives to enter.

\section{Discussion}

The findings of this study showed that the proportion of mothers who have geographic access to institutional delivery services was $68 \%$. This finding was similar to findings of studies conducted in rural Zambia and East Wollega zone in Ethiopia which showed about $67 \%$ and $69 \%$ of mothers having geographic access to institutional delivery services respectively $(18,19)$.

However, the finding of this study was higher than a study conducted in the Tsegedie district of the Tigray region in Ethiopia (20). This difference may be due to the fact that the latter study was conducted in 2013 , five years back, after which many health facilities might have been built close to the communities where mothers live.

This study found that the occupation of mothers was significantly associated with geographic accessibility to institutional delivery services. Employed mothers were 5 times more likely to have geographic accessibility to institutional delivery services when compared to mothers who were farmers. This could be due to the fact that employment is farmland in and around urban areas where government, non-government and private institutions are located and as a result, employed mothers live there where health facilities can be physically accessed within shorter distances.

This is supported by the qualitative finding in which a 28-year old uneducated mother from a rural area who delivered at home said, "... I am a farmer; I live in a very far village where our farm is located. If I am an educated and government employee, then I would have been living in the urban where I can easily go to a health facility for delivery. ....".The majority of the home-delivered mothers also shared the same point.

Number of ANC visits during the last pregnancy was also another variable that was significantly associated with geographic accessibility to institutional delivery services. Mothers who had 4 or more ANC visits during their last pregnancy were about 4 times more likely to have geographic accessibility to institutional delivery services when compared to mothers who had only a single ANC visit during their last pregnancy. This may be due to the fact that mothers who live closer to health facilities attend more ANC visits than mothers who live in remote areas.

A 32-year-old mother who delivered at a health center said, "... My home is only 10 minutes from the health center on foot walk. I went to the health center for ANC follow up 5 times before delivery. Even if my labor came at night, I delivered my baby at the health center. ..."

But few home-delivered mothers argued that "... we attend full ANC visits at nearby health posts; but since the health center is very far, we deliver at home especially when labor comes at night. ...". 
This study also revealed that the number of ANC visits during the last pregnancy was significantly associated with the perceived availability of institutional delivery services. This was supported by the qualitative finding in which a 39-year-old mother who delivered at health center said; "...the nurse who examined me during ANC visit told me many things about the importance of delivering at a health center. Then, I and my husband decided that I have to deliver at the health center. Two weeks before my delivery, I went to the health center to stay at the maternity waiting home. Then, I delivered my baby safely with the help of the nurse..."

Mothers whose households were graduated by HEWs as model families were about 1.5 times more likely to have perceived availability of IDS when compared to non-model families. This is evidenced by the qualitative finding in which the majority of the discussants in the health-development army leaders group said, "... we are model mothers in our village; we and our families have taken much training from the HEWs and now we are graduated. We have sufficient information about the presence of institutional delivery services at the nearby health center. We also teach our neighbors. If we don't have much information, we should not be model mothers..."

Mothers in the highest wealth quintile were about 12 times more likely to be able to afford institutional delivery services when compared to mothers in the lowest wealth quintile. Similarly, mothers in the fourth, middle and second wealth quintiles each were about 3 times more likely to be able to afford institutional delivery services when compared to mothers in the lowest wealth quintile. This may be due to the fact that households in the higher wealth quintiles have better material and financial assets that enable them to pay/afford for institutional delivery services without difficulty.

Mothers who had four or more ANC visits during their last pregnancy were about 3.5 times more likely to afford institutional delivery services when compared to mothers who had only one ANC visit. This may be due to the fact that mothers who fully attend ANC visits are economically better than those who attend less number of ANC visits. The qualitative finding supported this result in which a 26-year-old mother who completed primary education said, "... I have no problem with paying for any cost related to ANC visits or health facility delivery. My husband is a teacher and he earns a monthly salary. We can pay for transport or any related cost..."

Maternal educational level was revealed by this study to be significantly associated with the acceptability of institutional delivery services. Mothers who had attended secondary education and above were about 3 times more likely to accept institutional delivery services when compared to mothers who cannot read \& write. This is evidenced by the qualitative finding in which a 43-year-old home-delivered uneducated mother said, "...my mother and grandmother never knew health facilities. They all had delivered at home with no problem. God was with them. Now I have 6 children and I delivered them all at home without any problem. God, who saved my mother and grandmother, is always with me to help. ..."

Similarly, mothers who live in urban areas were about 3 times more likely to accept institutional delivery services when compared to mothers who live in rural areas. This may be due to the fact that urban mothers are less affected by the negative consequences of cultural beliefs and norms that hinder 
mothers from accepting institutional delivery as normal and safe. The other possible explanation may be the effect of different media that urban mothers are exposed to.

Graduation of mothers' $\mathrm{HH}$ as a model family by HEWs was also found as a significantly associated variable with the acceptability of institutional delivery services in this study. Mothers whose households were graduated as a model family by HEWs were 3 times more likely to accept institutional delivery services when compared to mothers of non-model families. The possible explanation for this fact may be model mothers are sufficiently worked on by health extension workers and their cultural perception on institutional delivery is positively changed.

This fact was supported by the qualitative finding in which majority of the discussants in the healthdevelopment army leaders group shared the same idea by saying;

“...in the past we trust Traditional Birth Attendants (TBAs) and we didn't go to the health center for delivery. Rather, we delivered at home with the help of TBAs and relatives. But, now we have trained by HEWs and we are model mothers in the village. We accept. We are modern mothers. If not, we are still backward. ..."

\section{Conclusions}

Moderate proportions of mothers have geographic accessibility to institutional delivery services but access to institutional delivery services in the other three dimensions of access was low. ANC visits of 4 and above, occupation of a mother when employed, and urban residence were independently associated factors with geographic accessibility to institutional delivery services. ANC visits of 4 and above, urban residence and graduation of mother's household as a model family were independently associated factors with perceived availability of institutional delivery services.

ANC visits of 4 and above, husband's occupation as employed and higher wealth quintiles of mother's household were independently associated factors with the affordability of institutional delivery services. Urban residence, graduation of mother's household as a model family and maternal education of secondary school and above were independently associated factors with the acceptability of institutional delivery services.

Thus, it was recommended that Health Extension Workersshould strengthen the provision of ANC service to all pregnant mothers and ensure that all mothers who started ANC follow up complete at least 4 visits before their delivery. HEW should also accelerate the training and graduation of model households. District and Zonal Education Office should give emphasis on female education to empower women through adult education for short term solutions and girl education for sustained long term solutions. The Federal Ministry of Health and Regional Health Bureaushould ensure geographic accessibility to all households in the community by building more healthcare facilities as close as possible to the communities. Future researchers should employ pure qualitative study in order to explore the full picture of the factors affecting the four dimensions of access to institutional delivery services. 


\section{List Of Abbreviations}

ANC: Antenatal Care, AOR: Adjusted Odds Ratio, Cl: Confidence Interval, COR: Crude Odds Ratio, EDHS: Ethiopian Demographic Health Survey, FGD: Focused Group Discussion, HEW: Health Extension Worker, HH: Household, HSTP: Health Sector Transformation Plan, IDS: Institutional Delivery Service, IRB: Institutional Review Board, MMR: Maternal Mortality Ratio, PCA: Principal Component Analysis, PSU: Primary Sampling Unit, SPSS: Statistical Package for Social Science, SSU: Secondary Sampling Unit, TBA: Traditional Birth Attendant, TSU: Tertiary Sampling Unit, TV: Television

\section{Declarations}

\section{Ethics Approval and Consent to Participate}

Ethical clearance was obtained from the Institutional Review Board (IRB) of Jimma University Institute of Health. Then, a permission letter was obtained from Jimma Zonal Health Department and each district health office. Written and signed informed consent was taken from each respondent before participation.

\section{Consent for Publication}

Not applicable.

\section{Availability of Data and Materials}

The datasets used and/or analyzed during the current study are available from the corresponding author on reasonable request.

\section{Competing Interests}

The authors declare that they have no competing interests.

\section{Funding}

The source of funding for this study was Jimma University Institute of Health. But the funding body has no role in the design of the study, collection, analysis, and interpretation of data and in writing the manuscript.

\section{Authors Contributions}

All authors have equally contributed to the conception, design, data acquisition, analysis and interpretation of the results. In addition, QQK prepared the manuscript and all the authors read and approved the final manuscript.

Acknowledgment 
The authors would like to thank Jimma University Department of Health Economics, Management and Policy for the kind cooperation in providing stationery materials and duplication of the questionnaire. The authors also like to express their gratitude towards Jimma Zone Health Department and respective district health offices for their genuine cooperation during the fieldwork without whose help the completion of this study would not have been realized.

\section{Authors Information}

QQK: Bachelor of Science Degree in Public Health, Master of Public Health in Health Service Management, Lecturer of Health Service Management, Department of Public Health, Mizan Tepi University, Ethiopia

WBS: Bachelor of Science Degree in Nursing, Master of Public Health in Health Service Management, Associate professor of health management, Director of Academic Quality Assurance and Reform of Health Institute, Department of Health policy and management, Jimma University, Ethiopia

TDW: Bachelor of Science Degree in Public Health, Master of Public Health in Health Service Management, Assistant Professor of Health Service Management, Department of Health policy and management, Jimma University, Ethiopia

\section{References}

1. Mclntyre D, Thiede M, Birch S. Access as a policy-relevant concept in low- and middle-income countries. Heal Econ Policy Law. 2009;4(2):179-93.

2. Borghi J, Storeng KT, Filippi V. Overview of the costs of obstetric care and the economic and social consequences for households. Stud HSO\&P. 2008;24:23-46.

3. Jacobs B, Ir P, Bigdeli M, Annear PL, Damme W Van. Addressing access barriers to health services: an analytical framework for selecting appropriate interventions in low-income Asian countries. 2011;

4. Kyei-Nimakoh M, Carolan-Olah M, Mccann T V. Access barriers to obstetric care at health facilities in sub-Saharan Africa-a systematic review. 2017;1-16.

5. Ganle JK, Fitzpatrick R, Otupiri E, Parker M. Addressing health system barriers to access to and use of skilled delivery services: perspectives from Ghana. 2016;(March 2015):235-53.

6. Abdella Amano, Abebaw Gebeyehu ZB. Institutional delivery service utilization in Munisa Woreda. 2012;

7. WHO. Maternal mortality fact sheet: available at http://www.searo.who.int/thailand/factsheets/fs0024/en/. 2014.

8. Central Statistical Agency (CSA) [Ethiopia] and ICF. Ethiopia Demographic and Health Survey 2016. Addis Ababa, Ethiopia, and Rockville, Maryland, USA: CSA and ICF. 2016;

9. Exavery A, Kanté AM, Njozi M, Tani K, Doctor H V, Hingora A, et al. Access to institutional delivery care and reasons for home delivery in three districts of Tanzania. 2014;1-11. 
10. Abeje G, Azage M, Setegn T. Factors associated with Institutional delivery service utilization among mothers in Bahir Dar City administration, Amhara region: a community-based cross-sectional study. Reprod Health [Internet]. 2014;11(1):1-7. Available from: Reproductive Health

11. Ayele DZ, Belayihun B, Teji K, Ayana DA. Factors Affecting Utilization of Maternal Health Care Services in Kombolcha District, Eastern Hararghe Zone, Oromia Regional State, Eastern Ethiopia. Hindawi. 2014;2014(2001).

12. Markos D, Odo DB, Shifti DM. Institutional Delivery Service Utilization and Associated Factors among Child-Bearing Age Women in Goba Woreda, Ethiopia Institutional delivery service utilization and associated factors among childbearing age women in Goba Woreda, Ethiopia. 2014;(October).

13. Abera M, Belachew T. PREDICTORS OF SAFE DELIVERY UTILIZATION IN ARSI ZONE, SOUTH-EAST ETHIOPIA. 2011;

14. Addisalem Fikre MD. Prevalence of institutional delivery and associated factors in Dodota Woreda. 2012.

15. FMoH. Health Sector Transformation Plan of Ethiopia. 2015.

16. WHO. Estimates of Unit Costs for Patient Services for Ethiopia. 2005.

17. WHO. Manual for the Household Survey to Measure Access and Use of Medicines. 2008.

18. Gabrysch S, Cousens S, Cox J, Campbell OMR. The Influence of Distance and Level of Care on Delivery Place in Rural Zambia: A Study of Linked National Data in a Geographic Information System. 2011;8(1).

19. Feyissa TR, Genemo GA. Determinants of Institutional Delivery among Childbearing Age Women in Western Ethiopia, 2013: Unmatched Case-Control Study. 2014;9(5):1-7.

20. Hailu D, Berhe H. Determinants of institutional childbirth service utilization among women of childbearing age in urban and rural areas of Tsegedie district, Ethiopia. Midwifery [Internet]. 2014;30(11):1109-17. Available from: http://dx.doi.org/10.1016/j.midw.2014.03.009

\section{Tables}

Table 1: Socio-demographic and economic characteristics of participants of mothers in Jimma zone, Southwest Ethiopia, $2018(n=593)$ 


\begin{tabular}{|c|c|c|c|c|}
\hline S.N & Characteristics & gory & Frequency & Percentage \\
\hline \multirow[t]{5}{*}{1} & \multirow[t]{5}{*}{ Age of mother } & $\leq 20$ & 27 & 4.6 \\
\hline & & $21-25$ & 99 & 16.7 \\
\hline & & $26-30$ & 211 & 35.6 \\
\hline & & $31-35$ & 147 & 24.8 \\
\hline & & $\geq 36$ & 109 & 18.4 \\
\hline \multirow[t]{3}{*}{2} & \multirow[t]{3}{*}{ Religion } & Muslim & 436 & 73.5 \\
\hline & & Orthodox & 104 & 17.5 \\
\hline & & Others $^{+}$ & 53 & 9 \\
\hline \multirow[t]{5}{*}{3} & \multirow[t]{5}{*}{ Ethnicity } & Oromo & 460 & 77.6 \\
\hline & & Dawuro/Wolaita & 47 & 8 \\
\hline & & Amhara & 43 & 7 \\
\hline & & Yem/Keffa & 25 & 4 \\
\hline & & Others $^{++}$ & 20 & 3.4 \\
\hline \multirow[t]{2}{*}{4} & \multirow[t]{2}{*}{ Residence } & Rural & 454 & 76.6 \\
\hline & & Urban & 139 & 23.4 \\
\hline \multirow[t]{2}{*}{5} & \multirow[t]{2}{*}{ Marital status } & Married/cohabiting & 583 & 98.3 \\
\hline & & Divorced/widowed & 10 & 1.7 \\
\hline \multirow[t]{2}{*}{6} & \multirow[t]{2}{*}{ Type marriage } & Monogamous & 541 & 91.9 \\
\hline & & Polygamous & 47 & 8.1 \\
\hline \multirow[t]{4}{*}{7} & \multirow[t]{4}{*}{ Mother's occupation } & Housewife & 292 & 49.2 \\
\hline & & Farmer & 229 & 38.6 \\
\hline & & Merchant/laborer & 40 & 6.8 \\
\hline & & Employee & 32 & 5.4 \\
\hline \multirow[t]{5}{*}{8} & \multirow[t]{5}{*}{ Husband's occupation } & Farmer & 413 & 69.6 \\
\hline & & Merchant & 78 & 13.2 \\
\hline & & Laborer & 51 & 8.6 \\
\hline & & Employee & 44 & 7.4 \\
\hline & & Others $^{+++}$ & 7 & 1.2 \\
\hline \multirow[t]{4}{*}{9} & \multirow[t]{4}{*}{ Mother's educational status } & Can't read \&write & 90 & 15.2 \\
\hline & & Can read \& write & 222 & 37.4 \\
\hline & & Primary education & 164 & 27.7 \\
\hline & & Secondary \& above & 117 & 19.7 \\
\hline \multirow[t]{4}{*}{10} & \multirow[t]{4}{*}{ Husband's educational status } & Can't read \&write & 43 & 7.3 \\
\hline & & Can read \& write & 194 & 32.7 \\
\hline & & Primary education & 223 & 37.6 \\
\hline & & Secondary \& above & 133 & 22.4 \\
\hline
\end{tabular}




\begin{tabular}{|l|l|l|l|l|}
\hline 4 & Household wealth index & Lowest quintile & 118 & 19.9 \\
\cline { 3 - 5 } & Second quintile & 119 & 20.1 \\
\cline { 3 - 5 } & Middle quintile & 119 & 20.1 \\
\cline { 3 - 5 } & Fourth quintile & 119 & 20.1 \\
\hline
\end{tabular}

${ }^{+}$Protestant \& Waqafata, ${ }^{++}$Tigre, Gurage \& Silte, ${ }^{+++}$Student, Sheik \& Priest

Table 2: Household level characteristics of mothers in Jimma zone, Southwest Ethiopia, $2018(n=593)$

\begin{tabular}{|l|l|l|l|l|}
\hline S.N & Characteristics & Category & Frequency & Percentage \\
\hline $\mathbf{1}$ & Family size & $\leq 5$ & 330 & 55.6 \\
\cline { 3 - 5 } & & $>5$ & 263 & 44.4 \\
\hline 2 & Head of household & Husband & 571 & 96.3 \\
\cline { 3 - 5 } & & Self & 22 & 3.7 \\
\hline 3 & \multirow{2}{*}{$\begin{array}{l}\text { Graduation of mother's HH as a model family } \\
\text { by HEWs }\end{array}$} & Yes & 280 & 47.2 \\
\cline { 3 - 5 } & & No & 313 & 52.8 \\
\hline
\end{tabular}

Table 3: Multivariable logistic regression of factors associated with geographic accessibility to institutional delivery services among mothers in Jimma zone, Southwest Ethiopia, 2018 


\begin{tabular}{|c|c|c|c|c|c|}
\hline \multicolumn{2}{|l|}{ Variables } & \multicolumn{2}{|c|}{$\begin{array}{l}\text { Travel time to the nearest health } \\
\text { facility on foot walk }\end{array}$} & \multirow{3}{*}{$\begin{array}{l}\text { COR }(95 \% \\
\text { CI }) \\
1.0\end{array}$} & \multirow{3}{*}{$\begin{array}{l}\text { AOR } \quad(95 \% \\
\text { CI) } \\
1.0\end{array}$} \\
\hline & & \multirow{2}{*}{$\begin{array}{l}60 \text { mins } \\
100(16.9 \%)\end{array}$} & \multirow{2}{*}{$\begin{array}{l}\leq 60 \text { mins } \\
129(21.8 \%)\end{array}$} & & \\
\hline \multirow{5}{*}{$\begin{array}{l}\text { Occupation of } \\
\text { mother }\end{array}$} & Farmer** & & & & \\
\hline & Housewife & $75(12.6 \%)$ & $217(36.6 \%)$ & $\begin{array}{l}2.24[1.54, \\
3.24]^{*}\end{array}$ & $\begin{array}{l}2.33[0.54 \\
3.54]\end{array}$ \\
\hline & Merchant & $1(0.2)$ & $20(3.4 \%)$ & $\begin{array}{l}15.50[0.04 \\
22.74]\end{array}$ & $\begin{array}{l}15.47[0.97, \\
20.99]\end{array}$ \\
\hline & Laborer & $8(1.3 \%)$ & $11(1.9 \%)$ & $\begin{array}{l}1.06[0.41, \\
2.74]\end{array}$ & $\begin{array}{l}1.14[0.41, \\
3.17]\end{array}$ \\
\hline & Employee & $4(0.7 \%)$ & $28(4.7 \%)$ & $\begin{array}{l}5.42[1.84 \\
15.97]^{*}\end{array}$ & $\begin{array}{l}5.10[1.63 \\
15.88]^{*}\end{array}$ \\
\hline \multirow[t]{2}{*}{ Residence } & Rural ** & $160(27.0 \%)$ & $294(49.6 \%)$ & 1.0 & 1.0 \\
\hline & Urban & $28(4.7 \%)$ & $111(18.7 \%)$ & $\begin{array}{l}2.15[1.36, \\
3.40]^{*}\end{array}$ & $\begin{array}{l}1.93[1.13 \\
3.29] *\end{array}$ \\
\hline \multirow{3}{*}{$\begin{array}{ll}\text { Number } & \text { of } \\
\text { ANC visits }\end{array}$} & $1 * *$ & $15(2.6 \%)$ & $12(2.0 \%)$ & 1.0 & 1.0 \\
\hline & $2-3$ & $72(12.3 \%)$ & $166(28.3 \%)$ & $\begin{array}{l}2.88[1.28 \\
6.46]^{*}\end{array}$ & $\begin{array}{l}3.0[1.26, \\
7.17]^{*}\end{array}$ \\
\hline & $\begin{array}{l}4 \text { and } \\
\text { above }\end{array}$ & $99(16.9 \%)$ & $222(37.9 \%)$ & $\begin{array}{l}2.79[1.26, \\
6.77]^{*}\end{array}$ & $\begin{array}{l}3.74[1.56, \\
8.98]^{*}\end{array}$ \\
\hline
\end{tabular}

*Statistically significant at $p<0.05$ $73 \%$

Hosmer and Lemeshow test: $p=0.624$

**Reference category

Classification power $=$ Nagelkerke $R$ square $=0.78$

Table 4: Multivariable logistic regression of factors associated with perceived availability of institutional delivery services in Jimma zone, Southwest Ethiopia, 2018 


\begin{tabular}{|c|c|c|c|c|c|}
\hline \multirow{2}{*}{\multicolumn{2}{|c|}{ Variables }} & \multicolumn{2}{|c|}{ Perceived availability } & \multirow{3}{*}{$\begin{array}{l}\text { COR } \\
(95 \% \mathrm{CI}) \\
1.0\end{array}$} & \multirow{2}{*}{$\begin{array}{l}\text { AOR } \\
(95 \% \mathrm{CI})\end{array}$} \\
\hline & & No & Yes & & \\
\hline \multirow[t]{3}{*}{ Number of ANC visits } & $1 * *$ & $22(3.8 \%)$ & $5(0.9 \%)$ & & \\
\hline & $2-3$ & $143(24.4 \%)$ & $95(16.2 \%)$ & $\begin{array}{l}\text { 2.92[1.07, } \\
7.98]^{*}\end{array}$ & $\begin{array}{l}2.59[0.94, \\
7.14]\end{array}$ \\
\hline & $\geq 4$ & $150(25.6 \%)$ & $171(29.1 \%)$ & $\begin{array}{l}\text { 4.98[1.84, } \\
13.49]^{*}\end{array}$ & $\begin{array}{l}3.80[1.38, \\
10.50]^{*}\end{array}$ \\
\hline \multirow[t]{2}{*}{ Residence } & $\begin{array}{l}\text { Rural } \\
* *\end{array}$ & $261(44.0 \%)$ & 193(32.5\%) & 1.0 & 1.0 \\
\hline & Urban & $59(9.9 \%)$ & $80(13.5 \%)$ & $\begin{array}{l}1.83[1.24, \\
2.69]^{*}\end{array}$ & $\begin{array}{l}\text { 1.74[1.17, } \\
2.59]^{*}\end{array}$ \\
\hline \multirow{2}{*}{$\begin{array}{l}\text { Graduation of mother's HH } \\
\text { as a model family }\end{array}$} & No ** & $187(31.5 \%)$ & $126(21.2 \%)$ & 1.0 & 1.0 \\
\hline & Yes & $133(22.4 \%)$ & $147(24.8 \%)$ & $\begin{array}{l}\text { 1.64[1.18, } \\
2.27]^{*}\end{array}$ & $\begin{array}{l}1.46[1.03, \\
2.06]^{*}\end{array}$ \\
\hline
\end{tabular}

*Statistically significant at $p \leq 0.05$

**Reference category Classification power= 60\% Hosmer and Lemeshow test: $p=0.283 \quad$ Nagelkerke $R$ square $=0.82 \quad H H=$ household

HEWs $=$ health extension workers

Table 5: Multivariable logistic regression of factors associated with the affordability of institutional delivery services in Jimma zone, Southwest Ethiopia, 2018 


\begin{tabular}{|c|c|c|c|c|c|}
\hline \multirow{2}{*}{\multicolumn{2}{|c|}{ Variables }} & \multicolumn{2}{|c|}{$\begin{array}{l}\text { Ability to afford the cost of } \\
\text { IDS }\end{array}$} & \multirow{2}{*}{$\begin{array}{l}\text { COR } \quad(95 \% \\
\text { CI })\end{array}$} & \multirow{2}{*}{$\begin{array}{l}\text { AOR } \quad(95 \% \\
\text { CI })\end{array}$} \\
\hline & & No & Yes & & \\
\hline \multirow[t]{5}{*}{ Wealth quintile } & Lowest ** & $95(16.0 \%)$ & $23(3.9 \%)$ & 1.0 & 1.0 \\
\hline & Second & $64(10.8 \%)$ & $55(9.3 \%)$ & $\begin{array}{l}3.55[1.98, \\
6.34]^{*}\end{array}$ & $\begin{array}{l}2.83[1.55, \\
5.16]^{*}\end{array}$ \\
\hline & Middle & $64(10.8 \%)$ & $55(9.3 \%)$ & $\begin{array}{l}3.55[1.98, \\
6.34]^{*}\end{array}$ & $\begin{array}{l}3.04[1.66, \\
5.58]^{*}\end{array}$ \\
\hline & Fourth & $63(10.6 \%)$ & $56(9.4 \%)$ & $\begin{array}{l}\text { 3.67[2.05, } \\
6.56]^{*}\end{array}$ & $\begin{array}{l}3.11[1.71, \\
5.68]^{*}\end{array}$ \\
\hline & Highest & $28(4.7 \%)$ & $90(15.2 \%)$ & $\begin{array}{l}\text { 13.27[7.12, } \\
24.73]^{*}\end{array}$ & $\begin{array}{l}11.60[6.02, \\
22.35]^{*}\end{array}$ \\
\hline \multirow{3}{*}{$\begin{array}{l}\text { Number of ANC } \\
\text { visits }\end{array}$} & $1 * *$ & $21(3.6 \%)$ & $6(1.0 \%)$ & 1.0 & 1.0 \\
\hline & $2-3$ & $123(21.0 \%)$ & $115(19.7 \%)$ & $\begin{array}{l}\text { 3.27[1.27, } \\
8.39]^{*}\end{array}$ & $\begin{array}{l}\text { 3.37[1.31, } \\
8.25]^{*}\end{array}$ \\
\hline & $\geq 4$ & 162(27.7\%) & $159(27.0 \%)$ & $\begin{array}{l}\text { 3.41[1.34, } \\
8.68]^{*}\end{array}$ & $\begin{array}{l}3.48[1.36, \\
9.61]^{*}\end{array}$ \\
\hline \multirow[t]{5}{*}{$\begin{array}{l}\text { Husband's } \\
\text { occupation }\end{array}$} & $\begin{array}{l}\text { Farmer } \\
\text { ** }\end{array}$ & $208(35.1 \%)$ & $205(34.6 \%)$ & 1.0 & 1.0 \\
\hline & Merchant & $51(8.6 \%)$ & $27(4.6 \%)$ & $\begin{array}{l}0.53[0.32, \\
1.89]\end{array}$ & $\begin{array}{l}0.44[0.25, \\
1.77]\end{array}$ \\
\hline & Laborer & $41(6.9 \%)$ & $10(1.7 \%)$ & $\begin{array}{l}0.24[0.12, \\
1.50]\end{array}$ & $\begin{array}{l}0.35[0.17, \\
2.76]\end{array}$ \\
\hline & Employee & $9(1.5 \%)$ & $35(5.9 \%)$ & $\begin{array}{l}\text { 3.94[1.85, } \\
8.41]^{*}\end{array}$ & $\begin{array}{l}3.63[1.51, \\
8.74]^{*}\end{array}$ \\
\hline & Other $^{+++}$ & $5(0.8 \%)$ & $2(0.3 \%)$ & $\begin{array}{l}0.40[0.07, \\
2.11]\end{array}$ & $\begin{array}{l}0.54[0.08, \\
3.32]\end{array}$ \\
\hline
\end{tabular}

*Statistically significant at $p \leq 0.05 \quad * *$ Reference category $\quad$ Classification power $=67.4 \%$ Hosmer and Lemeshow test: $p=0.50 \quad$ Nagelkerke $R$ square $=0.74 \quad{ }^{+++}$Student, Sheik \& Priest

Table 6: Multivariable logistic regression of factors associated with acceptability of IDS in Jimma zone, Southwest Ethiopia, 2018 


\begin{tabular}{|c|c|c|c|c|c|}
\hline \multirow{2}{*}{\multicolumn{2}{|c|}{ Variables }} & \multicolumn{2}{|c|}{ Acceptability of IDS } & \multirow{3}{*}{$\begin{array}{l}\text { COR } \\
(95 \% \mathrm{CI}) \\
1.0\end{array}$} & \multirow{2}{*}{$\begin{array}{l}\text { AOR } \\
(95 \% \mathrm{CI})\end{array}$} \\
\hline & & & Yes & & \\
\hline \multirow[t]{4}{*}{$\begin{array}{l}\text { Mother's } \\
\text { educational level }\end{array}$} & $\begin{array}{l}\text { Can't read \& } \\
\text { write** }\end{array}$ & $56(9.4 \%)$ & $34(5.7 \%)$ & & 1.0 \\
\hline & $\begin{array}{l}\text { Can read \& } \\
\text { write }\end{array}$ & $136(22.9 \%)$ & $86(14.5 \%)$ & $\begin{array}{l}1.04[0.62, \\
1.72]\end{array}$ & $\begin{array}{l}1.06[0.62, \\
1.79]\end{array}$ \\
\hline & $\begin{array}{l}\text { Primary } \\
\text { education }\end{array}$ & $99(16.7 \%)$ & $65(11.0 \%)$ & $\begin{array}{l}1.08[0.63, \\
1.83]\end{array}$ & $\begin{array}{l}1.06[0.61, \\
1.84]\end{array}$ \\
\hline & $\begin{array}{ll}\begin{array}{l}\text { Secondary } \\
\text { above }\end{array} & \& \\
\end{array}$ & $29(4.9 \%)$ & $88(14.8 \%)$ & $\begin{array}{l}4.99[2.74, \\
9.08]^{*}\end{array}$ & $\begin{array}{l}2.69[1.42, \\
5.09]^{*}\end{array}$ \\
\hline \multirow[t]{2}{*}{ Residence } & Rural** & $273(46.0 \%)$ & $181(30.5 \%)$ & 1.0 & 1.0 \\
\hline & Urban & $47(7.9 \%)$ & $92(15.5 \%)$ & $\begin{array}{l}2.95[1.98, \\
4.39]^{*}\end{array}$ & $\begin{array}{l}2.60[1.66, \\
4.08]^{*}\end{array}$ \\
\hline \multirow[t]{2}{*}{ HH model status } & No** & $213(35.9 \%)$ & $100(16.9 \%)$ & 1.0 & 1.0 \\
\hline & Yes & $107(18.0 \%)$ & $173(29.2 \%)$ & $\begin{array}{l}3.44[2.45, \\
4.83]^{*}\end{array}$ & $\begin{array}{l}3.12[2.16, \\
4.50]^{*}\end{array}$ \\
\hline
\end{tabular}

*statistically significant at $p \leq 0.05$

**Reference category Classification power $=$ 67.5\% Hosmer and Lemeshow test: $p=0.210 \quad$ Nagelkerke $R$ square $=0.87$

\section{Figures}

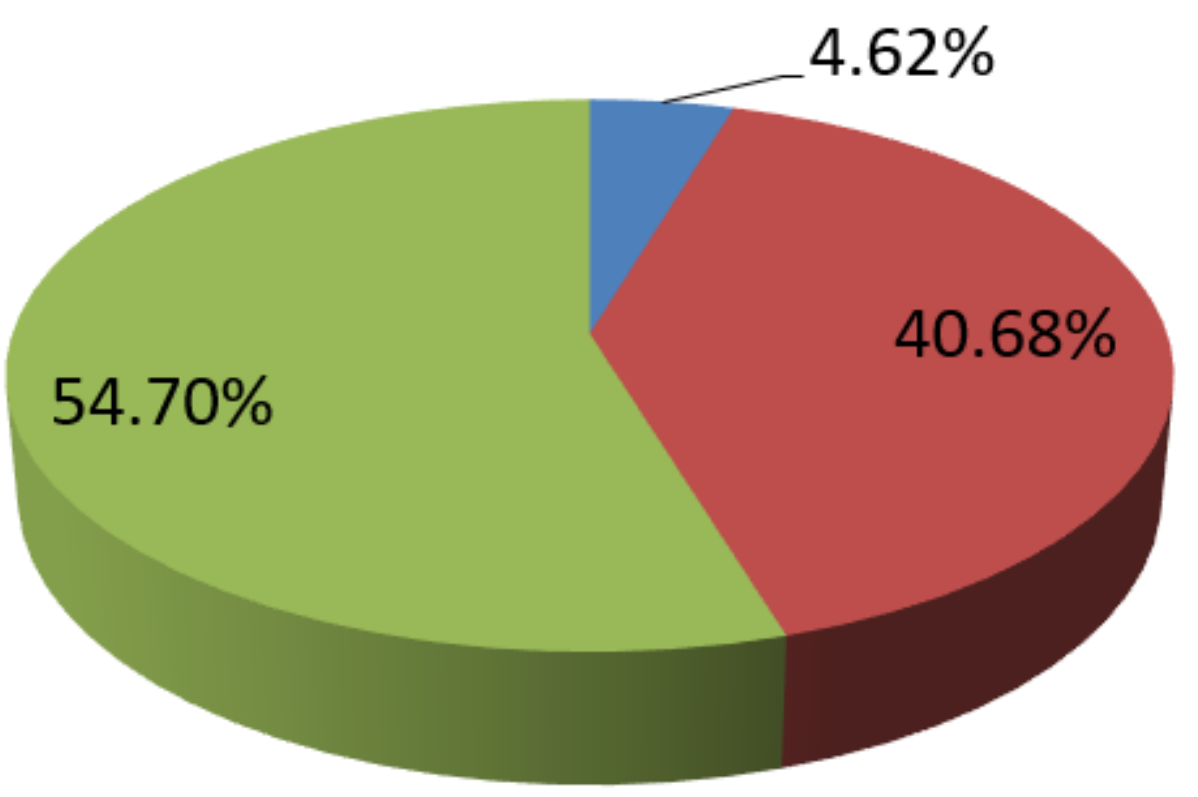

Number of

ANC visits

1

2 to 3

$\square 4$ 
Figure 1

Number of ANC visits during last pregnancy among mothers in Jimma zone, Southwest Ethiopia, 2018

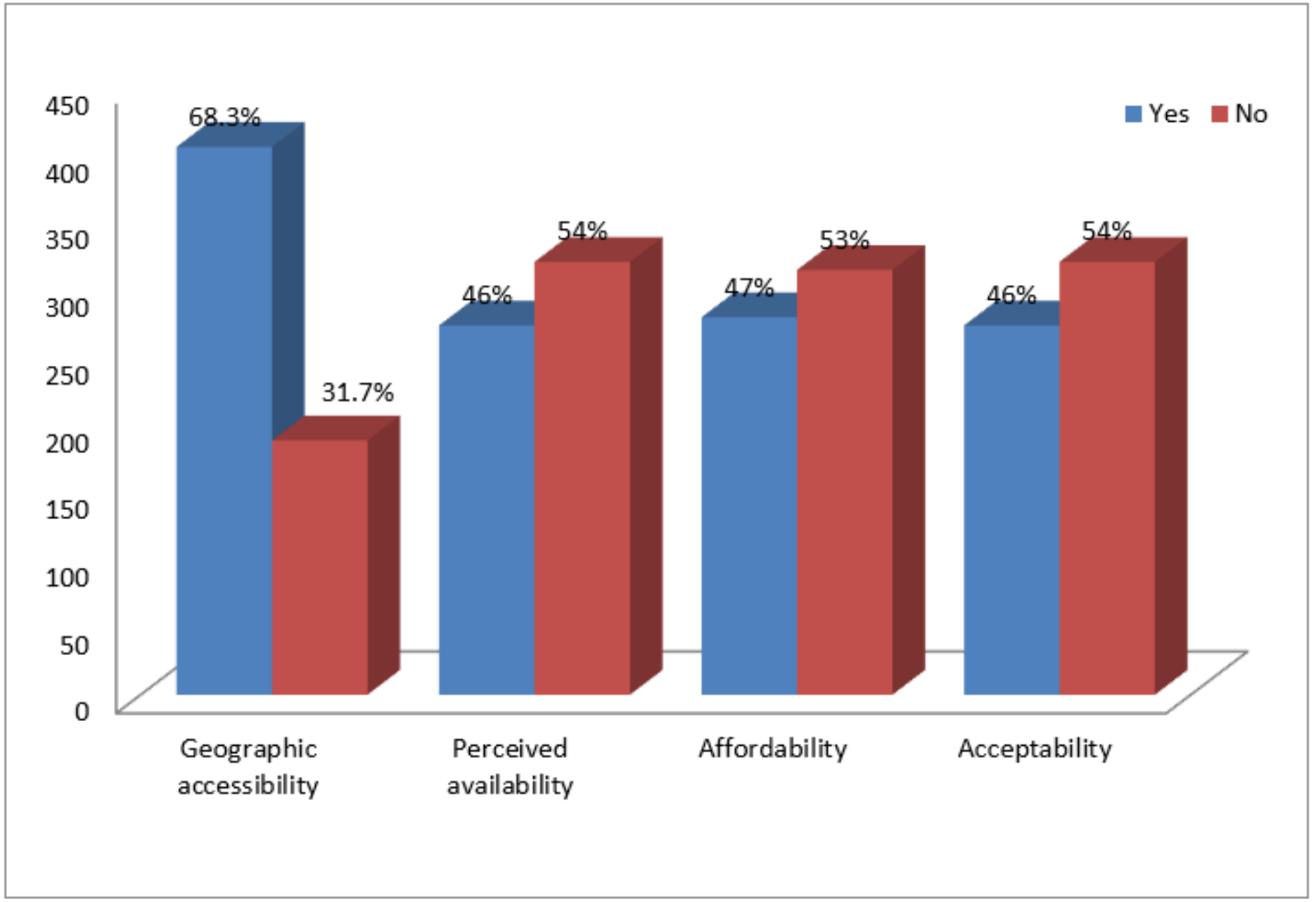

Figure 2

Dimensions of access to institutional delivery services among mothers in Jimma zone, Southwest Ethiopia, 2018 